\title{
Sensitivity of Puccinia graminis f. sp. tritici Isolates From China to Triadimefon and Cross-Resistance Against Diverse Fungicides
}

\author{
Xianxin Wu, ${ }^{1}$ Qiang Bian, ${ }^{2}$ Qiujun Lin, ${ }^{1}$ Qian Sun, ${ }^{1}$ Xinyu Ni, ${ }^{1}$ Xiaofeng Xu, ${ }^{1}$ Yongchun Qiu, ${ }^{1}$ Yuanhu Xuan, ${ }^{1}$ Yuanyin Cao, \\ and Tianya $\mathrm{Li}^{1}{ }^{1, \dagger}$ \\ ${ }^{1}$ College of Plant Protection, Shenyang Agricultural University, Shenyang, Liaoning 110866, China \\ ${ }^{2}$ National Pesticide Engineering Research Center, Nankai University, Tianjin 300071, China
}

Abstract

\begin{abstract}
Wheat stem rust caused by Puccinia graminis f. sp. tritici is an important wheat disease with sudden and devastating characteristics. The appearance and spread of new $P$. graminis f. sp. tritici races (Ug99, TKTTF, and TTTTF) have once again renewed the interest in the prevention and control of wheat stem rust. Fungicides can effectively control the epidemics of this disease in a short period of time. However, the fungal pathogen is prone to developing resistance. Therefore, we collected 89 isolates of $P$. graminis $\mathrm{f}$. sp. tritici from four provinces in China and used the spore germination method to test the sensitivity of the isolates to fungicide triadimefon. Seven relatively triadimefon-sensitive isolates and six relatively triadimefon-resistant isolates were further tested for sensitivity to fungicides carbendazim, mancozeb, thiophanate-methyl, and
\end{abstract}

kresoxim-methyl. The results showed that the mean concentration for $50 \%$ of maximal effect of the isolates to triadimefon was $16.14 \mathrm{mg} \cdot$ liter $^{-1}$, and the mean resistance factor was 4.48 . Only 29 isolates were resistant to triadimefon in which 27 isolates had low levels of resistance and 2 isolates had moderate levels of resistance. However, most of the 89 isolates had no resistance to triadimefon. There was a positive correlation between resistance to triadimefon and carbendazim, but there was no crossresistance between triadimefon resistance with thiophanate-methyl or kresoxim-methyl resistance. This study provides valuable information for managing fungicide resistant isolates of $P$. graminis $\mathrm{f}$. sp. tritici.

Keywords: fungicide resistance, stem rust, wheat
Wheat stem rust, caused by Puccinia graminis Pers.:Pers. f. sp. tritici Erikss. \& E. Henn., is a serious disease that has historically caused large yield losses worldwide (Pardey et al. 2013). Since 1970, the disease has been effectively controlled through the successful deployment of stem rust resistance genes (e.g., Sr31) in commercial wheat cultivars across the world (Cao et al. 2019; Rouse et al. 2012). The emergence of new virulent races of $P$. graminis f. sp. tritici has overcome some resistance genes of existing wheat cultivars and caused outbreaks of stem rust, which has posed a threat to global food security (Nazari et al. 2009; Olivera et al. 2015; Singh et al. 2011). For example, races TTKSK (Ug99), TKTTF, and TTTTF are virulent to most widely used stem rust resistance genes $\operatorname{Sr} 31$, SrTmp, and $S r 9 e+S r 13$, respectively, and they caused huge yield losses in eastern Africa and Sicily, Italy (Bhattacharya 2017; Food and Agricultural Organization of the United Nations [FAO] 2017; Olivera et al. 2015; Pretorius et al. 2000). Therefore, stem rust is again becoming a threat to wheat production worldwide.

Most Chinese wheat cultivars and breeding lines are highly susceptible to the races TTKSK (Ug99), TKTTF, and TTTTF of $P$.

${ }^{\dagger}$ Corresponding author: T. Y. Li; litianya11@syau.edu.cn

X. Wu, Q. Bian, and Q. Lin contributed equally to this work.

Funding: This study was supported by National Natural Science Foundation of China grant 31701738 .

*The $\boldsymbol{e}$-Xtra logo stands for "electronic extra" and indicates that two supplementary tables are published online.

The author(s) declare no conflict of interest.

Accepted for publication 8 March 2020.

(C) 2020 The American Phytopathological Society graminis f. sp. tritici (Cao et al. 2019; Li et al. 2016; Xu et al. 2017, 2018). If those races spread to China, they would cause large-scale epidemics of wheat stem rust, and the disease would be controlled by intensively using chemicals. The chemical control of wheat rusts in China has mainly depended on triazole fungicides (Song and Wang 2004; Ye et al. 2015). The most widely used triazole fungicide is triadimefon, which is an efficient and broad-spectrum ergosterol biosynthesis inhibitor. However, the long-term use of this single fungicide may lead to the development of resistant $P$. graminis f. sp. tritici isolates (Chen et al. 1990).

Chemical resistance in fungi is a serious problem to be solved in agricultural production. It has been reported that wheat leaf rust fungus ( $P$. triticina $\mathrm{f}$. sp. tritici), stripe rust fungus $(P$. striiformis $\mathrm{f} . \mathrm{sp}$. tritici), powdery mildew fungus (Blumeris graminis f. sp. tritici), and other fungal pathogens have resistance to triadimefon (Cao et al. 2008; Yang et al. 2013; Ye et al. 2015). However, it remains unclear whether $P$. graminis f. sp. tritici is resistant to triadimefon. Because wheat cultivars grown in China are highly susceptible to stem rust, it is particularly important to evaluate the risk of triadimefon resistance in the $P$. graminis f. sp. tritici population in China. In the present study, $P$. graminis f. sp. tritici isolates collected from the main wheat regions of China from 2013 to 2015 were tested for sensitivity to triadimefon and four other commonly used fungicides (thiophanate-methyl, mancozeb, kresoxim-methyl, and carbendazim). The findings provide a reference for monitoring triadimefon resistance in $P$. graminis f. sp. tritici, thereby providing a theoretical basis for the rational or rotational use of fungicides.

\section{Materials and Methods}

Fungicides. The following fungicides were used in this study: 97\% triadimefon (Kechuang Agricultural Chemical Co., Ltd.); 97\% thiophanate-methyl (Runze Chemical Co., Ltd.); 97\% mancozeb provided by Shenyang Institute of Chemical Industry; 50\% kresoxim-methyl WDG (BASF Co., Ltd.); and 98\% carbendazim provided by Shenyang Institute of Chemical Industry. 
$P$. graminis f. sp. tritici isolates and wheat cultivars. A total of 89 single-pustule isolates (including 66 from wheat and 23 originally collected from Berberis spp. by Prof. Zhensheng Kang's team at Northwest Agriculture \& Forestry University) from Heilongjiang, Liaoning, Sichuan, and Shaanxi provinces from 2013 to 2015 (Supplementary Table S1) were used in this study. Susceptible wheat cultivar Little Club (LC) used in this study was supplied by the College of Plant Protection, Shenyang Agricultural University.

Multiplication of $\boldsymbol{P}$. graminis $\mathbf{f}$. sp. tritici urediniospores. Seedlings of LC were grown in 12-cm-diameter porcelain pots to propagate $P$. graminis f. sp. tritici isolates. The leaves of 7-day-old seedlings were moistened with $0.05 \%$ Tween 20 using an atomizer. Then, urediniospores were gently smeared evenly onto the back sides of leaves with a flat toothpick and moistened again with $0.05 \%$ Tween 20. The inoculated seedlings were placed in a dew chamber for 16 to $20 \mathrm{~h}$ in the dark at 18 to $20^{\circ} \mathrm{C}$ before being transferred to a greenhouse bench at $20 \pm 1{ }^{\circ} \mathrm{C}$ with a photoperiod of $16 \mathrm{~h}$. Urediniospores were collected 14 days postinoculation and stored in a refrigerator at $4^{\circ} \mathrm{C}$ before use.

Determining resistance of $P$. graminis f. sp. tritici to triadimefon. Spore germination was used to determine the response of each isolate to triadimefon (Gullino and Garibaldi 1986). Briefly, triadimefon was dissolved in sterile water to prepare a $600 \mathrm{mg} \cdot \operatorname{liter}^{-1}$ solution. After the medium had cooled to $45^{\circ} \mathrm{C}$, the medium and the fungicide solution were mixed at different ratio to prepare plates with final fungicide concentrations of $3.25,7.5,15,30$, and $60 \mathrm{mg} \cdot \mathrm{liter}^{-1}$. The urediniospore suspension of $P$. graminis f. sp. tritici was evenly smeared with a cotton stick on the plates. Every concentration treatment had three replicates, and sterile water was used as the control. After $20 \mathrm{~h}$ ( $16 \mathrm{~h}$ in the dark followed by $4 \mathrm{~h}$ under fluorescent light) of incubation at $20 \pm 1{ }^{\circ} \mathrm{C}$, the spores were placed under a microscope (Leica DM500), and their germination rates were recorded. For each replicate, the germination status of 100 spores was scored. If the length of the germ tube was greater than or equal to the short diameter of the spore, it was recorded as germinated; otherwise, it was recorded as not germinated.

Calculating the half-maximal effective concentration of the fungicides. The relative inhibition rate of spores $=(1-$ mean germination rate of treated spore/mean germination rate of control spore) $\times 100 \%$.

The inhibition percentage of each treatment was calculated, and it was converted into the probability value $(y)$ using the table of "probability and death percentage." Then, the regression equation was obtained through regression analysis of the logarithmic $(x)$ and probability value $(y)$ of each treatment concentration. When $y=5$, the antilogarithm value of $x$ was the effective inhibition of halfmaximal effective concentration $\left(\mathrm{EC}_{50}\right)$ (Zhang et al. 2011).

Determining the baseline sensitivity of wheat to triadimefon. Because of the extensive use of triadimefon in wheat production, in nature it is not easy to collect isolates that are sensitive to triadimefon and can be used as controls. According to the literature, the $\mathrm{EC}_{50}$ (3.6 mg $\cdot$ liter $^{-1}$ ) of the most sensitive isolate of $P$. graminis f. sp. tritici in 1990 was taken as the baseline sensitivity (Chen et al. 1990). According to the formula, resistance index $(\mathrm{RI})=\mathrm{EC}_{50}$ of the tested isolate/EC $\mathrm{EC}_{50}$ of the sensitive isolate. An RI value $<5$ was considered sensitive, an RI value between 5 and 10 was considered low resistant, an RI value between 10 and 40 was considered moderately resistant, and an RI value $>40$ was considered highly resistant. The proportion of isolates with resistance level greater than five in the whole population was treated as the resistance frequency of the pathogen.

Cross-resistance between triadimefon and different fungicides. The spore germination method (Gullino and Garibaldi 1986) was used to determine the sensitivity of seven relatively triadimefonsensitive isolates and six relatively triadimefon-resistant isolates to four other fungicides: thiophanate-methyl, kresoxim-methyl, mancozeb, and carbendazim. The sensitivity correlations of triadimefon with carbendazim, ketoprim, thioprim, and mancozeb were determined using the $\mathrm{EC}_{50}$ values by regression analysis. The significance of the correlation coefficient was used to determine whether there was cross-resistance between triadimefon and the other four fungicides.

Data analysis. Software SPSS 11.0 was used for statistical analysis, and Duncan's new multiple range test was used to test the significance of the difference.

\section{Results}

Sensitivity of $P$. graminis f. sp. tritici populations to triadimefon in main wheat areas. The sensitivity of 89 isolates of $P$. graminis f. sp. tritici from four provinces in China to triadimefon was determined. As shown in Table 1, the mean $\mathrm{EC}_{50}$ value of the P. graminis f. sp. tritici isolates was $18.52 \mathrm{mg} \cdot \mathrm{liter}^{-1}$, and the mean resistance level was 5.14 , indicating that the $P$. graminis f. sp. tritici population in China generally has low resistance to triadimefon.

Table 1. Half-maximal effective concentration $\left(\mathrm{EC}_{50}\right)$ values and mean urediniospore inhibition rates of Puccinia graminis f. sp. tritici isolates from different provinces collected in 2013 to 2015 tested with triadimefon

\begin{tabular}{|c|c|c|c|c|}
\hline Location & Number & Range of $\mathbf{E C}_{50}\left(\mathrm{mg} \cdot\right.$ liter $\left.^{-1}\right)$ & Mean $\mathbf{E C}_{50}\left(\mathrm{mg} \cdot \text { liter }^{-1}\right)^{\mathbf{z}}$ & Mean inhibition rate $(\%)$ \\
\hline Yanting, Sichuan & 8 & $17.13-28.13$ & $23.52 \mathrm{a}$ & 93.47 \\
\hline Shaanxi & 23 & $9.82-40.30$ & $22.55 \mathrm{a}$ & 93.74 \\
\hline Heilongjiang & 7 & $10.94-27.06$ & $21.93 \mathrm{a}$ & 93.76 \\
\hline Maerkang, Sichuan & 11 & $11.46-21.86$ & $14.99 \mathrm{~b}$ & 95.80 \\
\hline Liaoning & 40 & $4.58-16.42$ & $9.61 \mathrm{c}$ & 97.18 \\
\hline
\end{tabular}

${ }^{\mathrm{z}}$ The same lowercase letter indicates no significant difference between the data $(P=0.05)$.

Table 2. Frequencies of different resistance index (RI) categories of Puccinia graminis f. sp. tritici isolates from different regions collected from 2013 to 2015 to triadimefon

\begin{tabular}{|c|c|c|c|c|c|c|}
\hline \multirow[b]{2}{*}{ Region } & \multicolumn{3}{|c|}{$\begin{array}{c}\text { Frequency }(\%) \text { of isolates in different RI } \\
\text { categories }\end{array}$} & \multirow[b]{2}{*}{ Mean RI } & \multirow[b]{2}{*}{ Highest RI ${ }^{\mathbf{y}}$} & \multirow[b]{2}{*}{ Frequency $(\%)$ of resistance } \\
\hline & $\mathrm{RI} \leq 5$ & $5<\mathrm{RI} \leq 10$ & $10<\mathrm{RI} \leq 40$ & & & \\
\hline Shaanxi & 30.43 & 60.87 & 8.70 & $6.26 \mathrm{a}^{\mathrm{z}}$ & $11.19 \mathrm{a}$ & 69.57 \\
\hline Yanting, Sichuan & 0.00 & 100.00 & 0.00 & $6.53 \mathrm{a}$ & $7.81 \mathrm{~b}$ & 100.00 \\
\hline Heilongjiang & 14.29 & 85.71 & 0.00 & $6.09 \mathrm{a}$ & $7.52 \mathrm{~b}$ & 85.71 \\
\hline Maerkang, Sichuan & 90.91 & 9.09 & 0.00 & $4.16 \mathrm{~b}$ & $6.07 \mathrm{c}$ & 9.09 \\
\hline Liaoning & 100.00 & 0.00 & 0.00 & $2.66 \mathrm{c}$ & $4.56 \mathrm{~d}$ & 0.00 \\
\hline Total & 66.29 & 31.46 & 2.25 & 5.14 & 11.19 & 33.71 \\
\hline
\end{tabular}

y The highest RI = the highest half-maximal effective concentration of tested isolate/the half-maximal effective concentration of sensitive isolate.

$\mathrm{z}$ The same lowercase letter means that there is no significant difference between data $(P=0.05)$. 
Isolates from different areas differed in their sensitivity to triadimefon. The $P$. graminis f. sp. tritici isolates from Yanting, Sichuan were the most sensitive, with the mean $\mathrm{EC}_{50}$ value of $23.52 \mathrm{mg} \cdot \mathrm{liter}^{-1}$ and a relative spore inhibition rate of $93.47 \%$. The mean $\mathrm{EC}_{50}$ values of the isolates from Shaanxi; Heilongjiang; Maerkang, Sichuan; and Liaoning were $22.55,22.45,15.10$, and $10.16 \mathrm{mg} \cdot$ liter $^{-1}$, respectively, and the inhibition rates were 93.76, 93.74, 95.80, and $99.18 \%$, respectively. Compared with the other regions, the isolates from Liaoning had the lowest mean $\mathrm{EC}_{50}$ value and the lowest mean inhibition rate or the highest sensitivity level $(P<0.05)$, and no fungicide-resistant isolate was found. The sensitivity of isolates in different areas of the same province was also significantly different. The mean $\mathrm{EC}_{50}$ value of isolates collected from Yanting, Sichuan was higher than that in the Maerkang region, which is also in Sichuan province. The sensitivity ranges of different isolates collected in the same area were also significantly different $(P<0.05)$. For example, the lowest $\mathrm{EC}_{50}$ value in Yanting was $17.13 \mathrm{mg} \cdot \mathrm{liter}^{-1}$, whereas the highest value was $28.13 \mathrm{mg} \cdot$ liter $^{-1}$ (Supplementary Table S1).

Resistance of $P$. graminis f. sp. tritici populations to triadimefon in the main wheat regions of China. The RI values to triadimefon in $P$. graminis f. sp. tritici from different regions are shown in Table 2. The results showed that about one-third of the tested $P$. graminis f. sp. tritici isolates had developed some level of resistance to triadimefon. The isolates with the highest RI values were collected from Shaanxi. It is worth mentioning that some of the $P$. graminis $\mathrm{f}$. sp. tritici isolates originally collected from Berberis spp. had an RI of 11.19 , and the sexually reproduced isolates in general had significantly higher RI values than those collected from wheat in the other regions. The isolates collected from Liaoning were the most sensitive to triadimefon (the mean RI is 2.83), and all of the isolates were in the sensitive range $(\mathrm{RI}<5)$. In addition, $>90 \%$ of the isolates from Maerkang were sensitive to triadimefon. The isolates from the Yanting area of Sichuan had low levels of triadimefon resistance.

Only 2 of the 89 isolates of $P$. graminis f. sp. tritici had a moderate level of triadimefon resistance, and they were from Shaanxi. According to the frequency distribution of resistance levels, $33.71 \%$ of the tested isolates had low to moderate levels of resistance to triadimefon, and the isolates with moderate resistance were only $2.25 \%$. The results indicated that most isolates were not resistant to triadimefon.

Cross-resistance between triadimefon and other fungicides. The mean urediniospore inhibition rates of tested fungicides to $P$. graminis f. sp. tritici isolates were presented in Table 3. Triadimefon and thiophanate-methyl had high inhibition rates to tested $P$. graminis

Table 3. Half-maximal effective concentration $\left(\mathrm{EC}_{50}\right)$ values and mean urediniospore inhibition rates of Puccinia graminis f. sp. tritici isolates to tested fungicides

\begin{tabular}{|c|c|c|c|}
\hline Fungicide & Range of $\mathrm{EC}_{50}\left(\mathrm{mg} \cdot\right.$ liter $\left.^{-1}\right)$ & Mean $\mathrm{EC}_{50}\left(\mathrm{mg} \cdot \text { liter }^{-1}\right)^{\mathrm{z}}$ & Mean inhibition rate (\%) \\
\hline Carbendazim & $29.37-85.74$ & $56.26 \mathrm{a}$ & 83.49 \\
\hline Triadimefon & $7.13-37.17$ & $18.96 \mathrm{~b}$ & 94.21 \\
\hline Thiophanate-methyl & $0.51-11.57$ & $3.77 \mathrm{c}$ & 90.85 \\
\hline Mancozeb & $0.06-0.35$ & $0.16 \mathrm{c}$ & 87.69 \\
\hline Kresoxim-methyl & $0.01-0.22$ & $0.05 \mathrm{c}$ & 85.26 \\
\hline
\end{tabular}

${ }^{\mathrm{z}}$ The same lowercase letter indicates no significant difference between the data $(P=0.05)$.

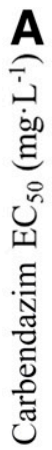

160
140
120
100
80
60
40
20
0

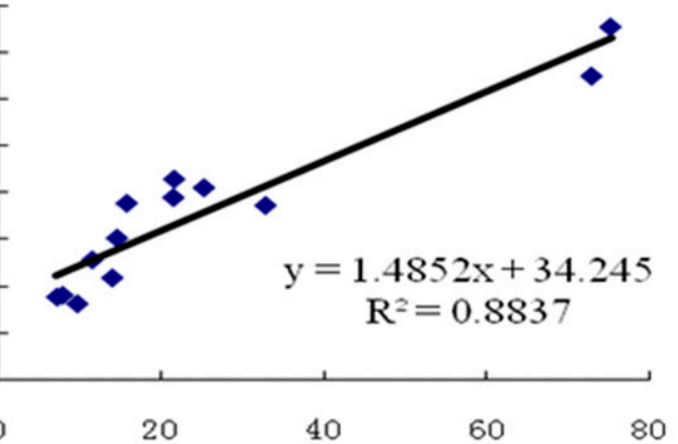

Triadimefon $\mathrm{EC}_{50}\left(\mathrm{mg} \cdot \mathrm{L}^{-1}\right)$

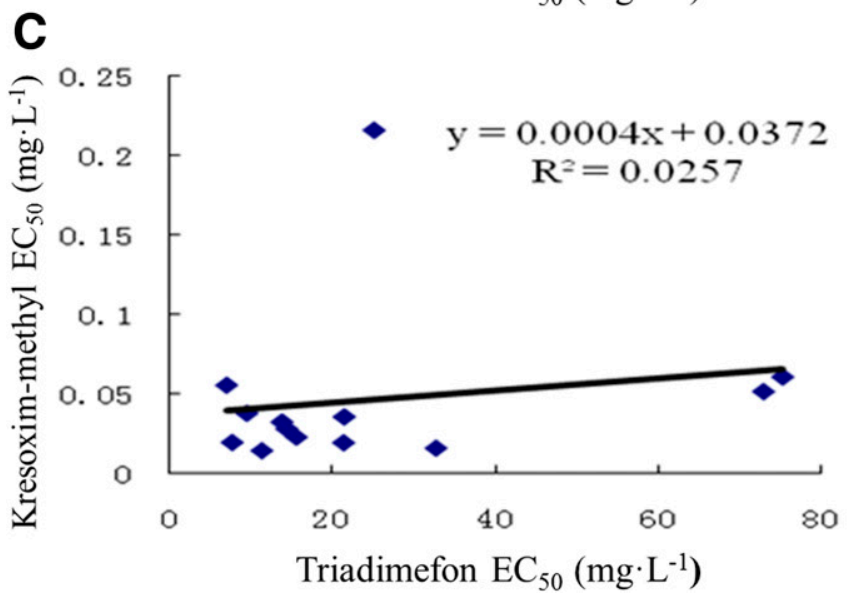

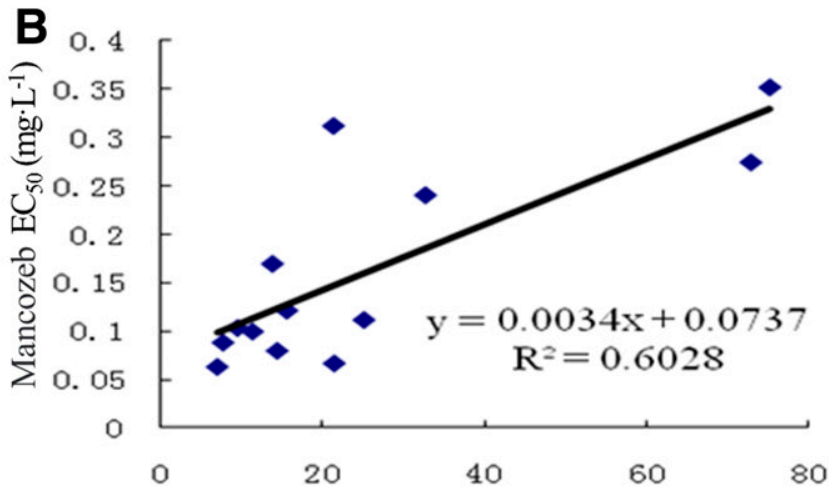

Triadimefon $\mathrm{EC}_{50}\left(\mathrm{mg} \cdot \mathrm{L}^{-1}\right)$

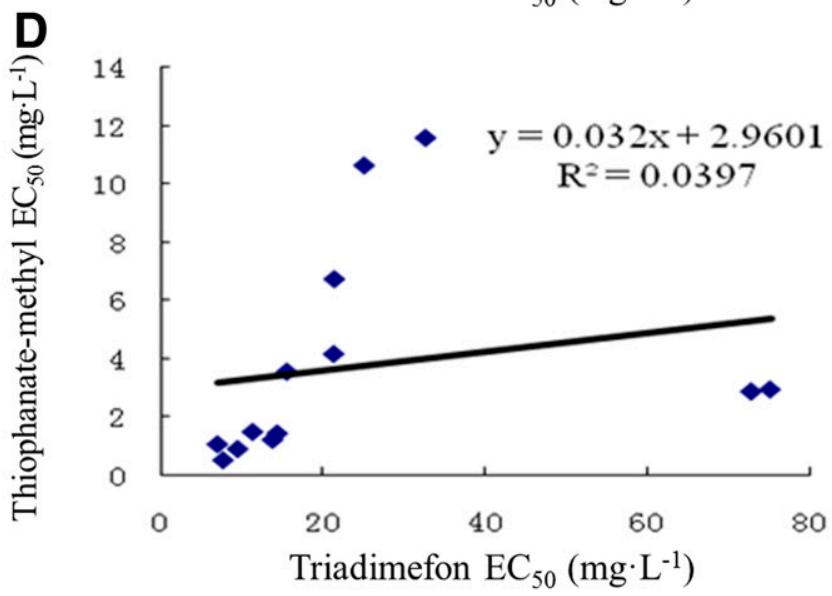

Fig. 1. Cross-resistance between different fungicides. A, Cross-resistance between triadimefon and carbendazim. B, Cross-resistance between triadimefon and mancozeb. C, Cross-resistance between triadimefon and kresoxim-methyl. D, Cross-resistance between triadimefon and thiophanate-methyl. EC ${ }_{50}$, half-maximal effective concentration. 
f. sp. tritici isolates. The correlation coefficients of 13 isolates were all $>0.94$, indicating that all $\mathrm{EC}_{50}$ values were reliable (Supplementary Table S2). Therefore, the results of the cross-resistance between triadimefon and the other four fungicides based on $\mathrm{EC}_{50}$ were also reliable. The correlation analysis showed that there was a significant positive correlation between the sensitivities of $P$. graminis f. sp. tritici to triadimefon and carbendazim $(r=0.9411$, $P<0.001)$ (Fig. 1A), indicating that most isolates were sensitive to both fungicides and that some isolates had cross-resistance to both triadimefon and carbendazim. There was also a certain correlation between the sensitivities to triadimefon and mancozeb $(r=0.7764$, $P=0.002<0.05$ ) (Fig. 1B). However, there was no significant correlation between the sensitivities to triadimefon and kresoximmethyl $(r=0.1992, P>0.05)$ or between triadimefon and thiophanate-methyl $(r=0.1603, P>0.05)$ (Fig. 1C and D). These results indicated that there was no cross-resistance between triadimefon and thiophanate-methyl or kresoxim-methyl.

\section{Discussion}

Triazole fungicides exert high selection pressure on fungal pathogens. Because this group of fungicides has been used for a long period of time, many pathogens have developed resistance. It has been reported that fungal pathogen populations have crossresistance to triazole fungicides and sterol demethylation inhibitors (Collins and Brown 1999). If $P$. graminis f. sp. tritici resistance to these fungicides becomes widespread in the field, it will bring huge losses to fungicide manufacturers and agricultural production. At present, triadimefon is still the main fungicide used for the control of wheat rusts, and a large amount of triadimefon is applied in fields every year in China. Therefore, we should pay attention to the emergence of fungicide-resistant isolates. Prolonging the effective life of triazole fungicides by delaying the development of pathogen resistance is an urgent task.

In this study, the maximum $\mathrm{EC}_{50}$ value of 89 P. graminis $\mathrm{f}$. sp. tritici isolates from different wheat-producing areas in China was 8.81 times the minimum $\mathrm{EC}_{50}$ value. This range in $\mathrm{EC}_{50}$ values might be because of the natural differences among sensitive isolates or differences in the environments that the isolates were collected from. Based on the distribution of resistance-level frequency, the triadimefon-sensitive isolates were dominant in the field, and few isolates had a moderate level of resistance, indicating that the $P$. graminis f. sp. tritici population in China is not resistant to triadimefon at present. This might be the reason why triadimefon has been so successful in controlling wheat stem rust over the last few decades.

In the future, it will be necessary to monitor whether $P$. graminis $\mathrm{f}$. sp. tritici in the field is resistant to triadimefon. To achieve this, researchers should take a large number of samples from wheat fields that are often treated with triadimefon and conduct in-depth investigations. At the same time, we should follow the example of the efforts to control wheat powdery mildew by establishing a mature fungicide resistance monitoring system, carrying out field resistance monitoring every year, and determining whether fungicide-resistant isolates exist. These measures would provide a theoretical basis for managing fungicide resistance in $P$. graminis f. sp. tritici and provide guidance for the production and use of fungicides.

In this study, we also tested $P$. graminis f. sp. tritici for sensitivity to other chemicals. Triadimefon and thiophanate-methyl had high inhibition rates to the tested $P$. graminis f. sp. tritici isolates. Although the fungicide concentrations used in the study were lower than those used in the field, the inhibition rate of urediniospores was still very high. This is expected because urediniospores were immediately and directly put in contact with the fungicide. Under field conditions, much of the applied fungicide may drop to the ground. A higher than inhibiting rate is needed to keep an adequate concentration on plants for a much longer period of time than the period that we tested in this study. Our data indicated that there was possible cross-resistance between triadimefon and carbendazim. However, only two isolates showed some level of resistance to these fungicides. Further tests with more isolates are needed to verify cross-resistance. Practically, the mixed use or alternate use of triadimefon and carbendazim in crop production should be avoided to preserve the control efficiency of the two fungicides. At present, there is no cross-resistance between triadimefon and thiophanate-methyl or kresoxim-methyl, and therefore, thiophanate-methyl and kresoxim-methyl may be used instead of triadimefon to control wheat stem rust in some areas where the $P$. graminis f. sp. tritici population is largely resistant to triadimefon. Triadimefon may also alternately used with thiophanate-methyl or kresoxim-methyl in wheat production in other areas to prolong the service life of the triadimefon and ensure that the pathogen is effectively controlled.

\section{Acknowledgments}

We appreciate Dr. Zhensheng Kang at Northwest Agriculture \& Forestry University in China for providing aeciospores from barberry and the great deal of effort made by our colleagues to get samples in different locations.

\section{Literature Cited}

Bhattacharya, S. 2017. Deadly new wheat disease threatens Europe's crops. Nature 542:145-146

Cao, X. R., Zhao, W. J., and Zhou, Y. L. 2008. Monitoring of resistance of Blumeria graminis f. sp. tritici isolates to triadimefon in 2007. Plant Prot. 34:74-77.

Cao, Y. Y., Si, B. B., Zhu, G. Q., Xu, X. F., Li, W. H., Chen, S., Zhao, J., and Li, T. Y. 2019. Race and virulence of asexual and sexual populations of Puccinia graminis $\mathrm{f}$. sp. tritici in China from 2009 to 2015. Eur. J. Plant Pathol. 153:545-555.

Chen, Y. L., Zhang, S. X., Chen, W. Q., and Yang, L. P. 1990. Preliminary study on sensitivity of wheat rust (Puccinia striiformis West, Puccinia recondite Var. tritici Erikss. et Henn, Puccinia graminis Var. tritici Erikss et Henn) to triademefom. Acta Phytopathol. Sin. 22:95.

Collins, P., and Brown, J. K. M. 1999. Resistance and cross resistance of Erysiphe graminis to triazole and morpholine fungicides. The First International Powdery Mildew Conference, France.

Food and Agricultural Organization of the United Nations (FAO). 2017. Spread of Damaging Wheat Rust Continues: New Races Found in Europe, Africa, and Central Asia. http://www.fao.org/news/story/en/item/469467/icode/

Gullino, M. L., and Garibaldi, A. 1986. Fungicide resistance monitoring as an aid to tomato grey mould management. Pages 499-505 in: 1986 British Crop Protection Conference, Pests and Diseases. British Crop Protection Council, Thornton Heath, UK.

Li, T. Y., Cao, Y. Y., Wu, X. X., Xu, X. F., and Wang, W. L. 2016. Seedling resistance to stem rust and molecular marker analysis of resistance genes in wheat cultivars of Yunnan, China. PLoS One 11:e0165640.

Nazari, K., Mafi, M., Yahyaoui, A., Singh, R. P., and Park, R. F. 2009. Detection of wheat stem rust race (Puccinia graminis f. sp. tritici) TTKSK (Ug99) in Iran Plant Dis. 93:317.

Olivera, P., Newcomb, M., Szabo, L. J., Rouse, M., Johnson, J., Gale, S., Luster, D. G., Hodson, D., Cox, J. A., Burgin, L., Hort, M., Gilligan, C. A., Patpour, M., Justesen, A. F., Hovmøller, M. S., Woldeab, G., Hailu, E., Hundie, B., Tadesse, K., Pumphrey, M., Singh, R. P., and Jin, Y. 2015. Phenotypic and genotypic characterization of race TKTTF of Puccinia graminis f. sp. tritici that caused a wheat stem rust epidemic in southern Ethiopia in 2013-14. Phytopathology 105:917-928.

Pardey, P. G., Beddow, J. M., Kriticos, D. J., Hurley, T. M., Park, R. F., Duveiller, E., Sutherst, R. W., Burdon, J. J., and Hodson, D. 2013. Right-sizing stem-rust research. Science 340:147-148.

Pretorius, Z. A., Singh, R. P., Wagoire, W. W., and Payne, T. S. 2000. Detection of virulence to wheat stem rust resistance gene Sr31 in Puccinia graminis f. sp. tritici in Uganda. Plant Dis. 84:203.

Rouse, M. N., Nava, I. C., Chao, S., Anderson, J. A., and Jin, Y. 2012. Identification of markers linked to the race $\mathrm{Ug} 99$ effective stem rust resistance gene $\operatorname{Sr} 28$ in wheat (Triticum aestivum L.). Theor. Appl. Genet. 125:877-885.

Singh, R. P., Hodson, D. P., Huerta-Espino, J., Jin, Y., Bhavani, S., Njau, P., Herrera-Foessel, S., Singh, P. K., Singh, S., and Govindan, V. 2011. The emergence of Ug99 races of the stem rust fungus is a threat to world wheat production. Annu. Rev. Phytopathol. 49:465-481.

Song, Y. L., and Wang, R. F. 2004. Advances in chemical control of wheat diseases. J. Henan Agric. Sci. 7:50-51.

Xu, X. F., Li, D. D., Liu, Y., Gao, Y., Wang, Z. Y., Ma, Y. C., Yang, S., Cao, Y. Y., Xuan, Y. H., and Li, T. Y. 2017. Evaluation and identification of stem rust resistance genes $\mathrm{Sr} 2, \mathrm{Sr} 24, \mathrm{Sr} 25, \mathrm{Sr} 26, \mathrm{Sr} 31$ and $\mathrm{Sr} 38$ in wheat lines from Gansu Province in China. PeerJ 5:e4146.

Xu, X. F., Yuan, D. P., Li, D. D., Gao, Y., Wang, Z. Y., Liu, Y., Wang, S. T., Xuan, Y. H., Zhao, H., Li, T. Y., and Wu, Y. H. 2018. Identification of stem rust resistance genes in wheat cultivars in China using molecular markers. PeerJ 6:e4882.

Yang, L., Zhou, Y. L., Duan, X. Y., Cao, X. R., and Zou, Y. F. 2013. Sensitivity of Blumeria graminis $\mathrm{f}$. sp. tritici isolates to triadimenfon and fenpropidin in China in 2011. Acta Phytopathol. Sin. 43:430-434.

Ye, Q. S., Xiao, N. W., Zhang, F., Cai, G. L., and Yang, L. J. 2015. Research on precise monitor and chemical control of wheat stripe rust in Shiyan. Hubei Agric. Sci. 54:5603-5606.

Zhang, N., Kang, X. H., Pen, Y. J., and Wu, G. P. 2011. Monitoring of resistance of Puccinia striiformis f. sp. tritici isolates to triadimefon. J. Anhui Agric. Sci. 39: 18608-18609. 